\title{
The Use of Information and Communication Technology in Educational Management in the 21st Century for Higher Education Trend in China
}

\author{
Shuwu $\mathrm{Li}^{1}$, Libao Luo ${ }^{1}$ \\ Guangxi Science \& Technology Normal University, 546199 Laibin, Guangxi, China \\ *Mengdi Wang. Email: 419097818@qq.com
}

\begin{abstract}
According to official figures, China's GDP has increased every year since 2010. As China's national strength grows, its influence in the world grows. The economic growth of developed countries cannot be separated from the improvement of information and communication technology (ICT). As a developing country, China cannot avoid the application of information and communication technology in various fields. In particular, the application in the field of education is inseparable. This paper summarizes the historical process of communication technology in the field of education in China and speculates the future development trend. It is hoped that this speculation can provide some reference value for the further application of information technology in the education field. For example, the application of ICT in education management contributes to environmental protection, minimizing the use of paper in managment field. Basically, many departments have achieved paperless office in daily management. In addition, the platform between departments on campus is more deeply integrated to provide a trend reference.
\end{abstract}

Keywords: ICT, China, Education management, Higher education trend

\section{INTRODUCTION}

UNESCO has defined ICT as forms of technology that are used to transmit, process, store, creae, display, share or exchange information by electronic means. It includes not only traditional technologies like radio and television, but also modern ones like cellular phones, computer and network, hardware and software, satellite systems and so on, as well as the various services and applications associated with them, such as Video conferencing ${ }^{[1]}$.

Information communications technology (ICT) has the potential to increase the productivity and economic growth of a country. The World Bank Group (WBG) (2012) has been encouraging innovations in ICT as it seems to increase a country's competitiveness and enable economic opportunities for more IT-based services industry within the country ${ }^{[2]}$. China is a developing country with rapid economic development. From 2010 to 2020, China's GDP and per capita disposable have been increasing year by year. See the Figure 1.

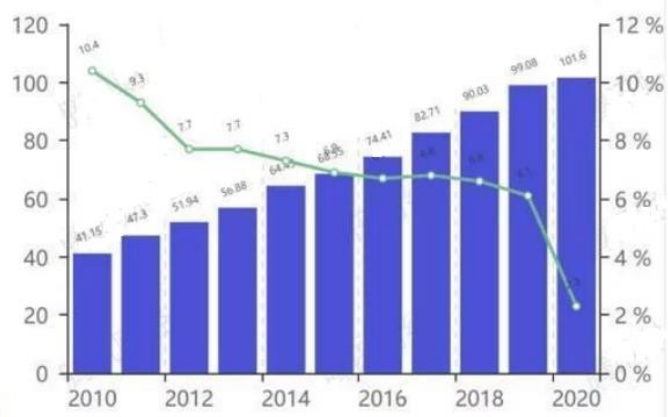

Figure 1 GDP (Trillion RMB) from the National Bureau of Statistics

The development of science and technology is inseparable from the cultivation of talents. Especially with the advent of $5 \mathrm{G}$ era and the key points of work of the Ministry of Education in 2021, the goal and task of actively promoting the construction of education informatization is to accelerate the high-quality development of education informatization, actively develop "Internet + education", and comprehensively guarantee the network security of the education system. Work measures include: the issuance of the Medium - 
and Long-Term Development Plan for Educational Informatization (2021-2035) and the Fourteenth FiveYear Plan for Educational Informatization, and the convening of the third National Conference on Educational Informatization. Guiding opinions are issued on promoting the development of "Internet Plus Education" [3]. We will promote the construction of new educational facilities and study the construction of a high-quality education support system, with a focus on informationization and with the goal of improving quality. We will fully implement the action plan for informationization 2.0 in education, accelerate the construction of a private education network, and popularize the construction and application of digital campuses. It is self-evident that ICT will be applied and integrated in the field of education deeply in the future. Based on the literature method, this paper sorted out the past, present and future application trend of information technology in education management by collecting relevant articles at home and abroad, providing some reference for the further in-depth research in this field.

\section{ICT USE IN EDUCATIONAL MANAGEMENT}

Role of ICT in School Administration is divided into four parts: record keeping, scheduling, communicating with parents, and school management tools ${ }^{[1]}$. From these four roles, the function can be simply summarized into recording, scheduling, communicating and tooling. The function possibly gives a direction to track the path of the use of the ICT in educational in management. From the Springer and CNKI index, the satisfactory material could be found less. Some discuss problems that arise in use and some talk about its use in teaching, while this article mainly wants to explore its use in educational management. Based on this above, this article divides the use of ICT into three steps: computer popularity, platform with Apps and ICT integration. The details are as follows

\subsection{Computer Popularity}

Talent training The popularization of computer in China has gone through three stages. The first stage of the penetration point is mainly computer high-level languages (BASIC and FORTRAN). The main students are divided into three categories: non-computer science teachers and students, some on-the-job scientific and technological personnel and managerial personnel. The second popularity came in the 1990s with the advent of the microcomputer and software such as Windows and Office. The third popularization is in 21st century, and the application of network is in focus. After three times of popularization, we can draw a small conclusion that the application of the rudiments of ICT in the educational management of colleges and universities is basically based on the functions of computer hardware and Office software. A computer mainly performs the following

four functions ${ }^{[1]}$ :

-Receive input - accept information from outside

through various input devices like keyboard,

mouse etc.

-Process information - perform arithmetic or

logical operations on the information.

-Produce output - communicate information to

the outside world through output devices like

monitor, printer etc.

-Store information - store the information in

storage devices like hard disk, compact disk etc.

\subsection{Platform with Apps}

When the computer was popularized for the third time, China entered the E era, and the application of information technology went deep into all fields, including the education field. See Figure 2.

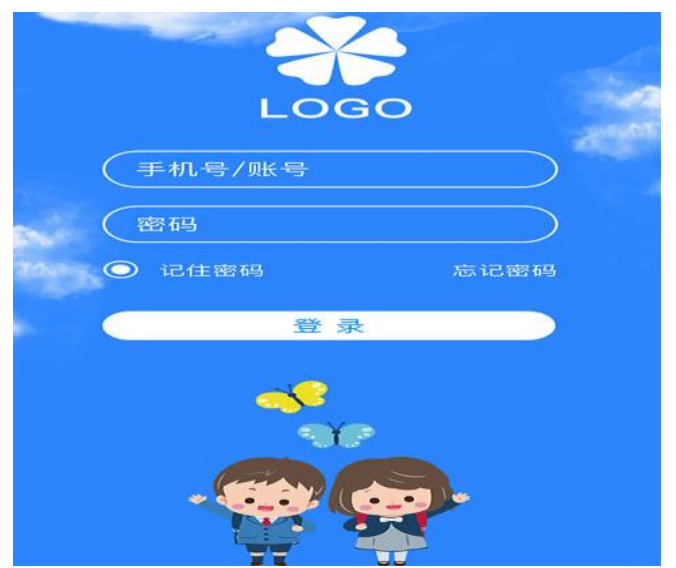

Figure 2 A Chinese Teaching Platform with Apps Sourced by Baidu

In this period, the biggest feature of ICT application in education management is the platform use accompanying with Apps in intelligent mobile phones. Realizing the paperless management process is the important idea and goal of management in this era. The application of ICT in educational management at this time is in line with this concept and goal. ICT use in educational management is as follows: 


\subsection{Application in teaching management}

\subsubsection{The application of ICT in practical teaching}

The traditional teaching method is based on knowledge "instilling", but in the information perspective, in order to enable students to get a more comprehensive development, teaching should be based on the impart of theoretical knowledge, according to the needs of students to carry out personalized teaching. The application of information technology is conducive to the effective implementation of personalized teaching. In actual teaching, schools and teachers can adopt individualized teaching forms according to the actual situation of students. Teachers not only can provide students with learning tasks to consolidate the foundation and appropriate learning resources through the teaching information platform, so that students can continuously strengthen the basic theory; but also can master students' learning through the network teaching platform, and provide students with timely and effective teaching guidance.

\subsection{1,2. Application of ICT in teaching quality analysis}

The school uses information technology to analyze the teaching quality, which is one of the effective ways to obtain the results of teaching quality analysis. After the final or other formal examinations, schools can make scientific and reasonable adjustments to the teaching work through the analysis of the teaching quality, so as to ensure the teaching quality of the school. The application of ICT greatly improves the objectivity and pertinence of teaching evaluation. The biggest effect is to reduce the use of a lot of paper forms before. You can directly get the desired data and analysis charts from the platform.

\subsubsection{Application in educational administration management}

\subsubsection{Management of teachers' routine and teaching process}

At the end of a semester, the academic affairs office will generally assign teaching tasks to teachers, and information technology will be used in the process of assigning tasks. The school will upload the tasks that teachers need to complete to the Internet through the comprehensive educational administration management platform and the department as a unit, and then the teachers will download the required knowledge and materials through the Internet after the teachers know the teaching tasks clearly, and then reasonably allocate their teaching tasks according to the curriculum schedule in the second semester. In recent years, Chinese universities have been expanding their campuses, sometimes across cities. Without the application of ICT in management, it is impossible to realize the effective management and assignment of tasks across time and space, and across multiple people.

\subsubsection{Management of teachers' routine and teaching process}

Before the new semester began, the educational administration personnel will formulate teaching, technology teaching plans, course teaching plan and PPT, video and other professional teachers released to the educational administration management system. Through their own password, students can select the content to download. Teachers can upload their courseware and check the teaching tasks from the management platform and mobile Apps, while students can also check their course arrangement of this semester from the management platform and mobile APP. In particular, teachers can also use the Apps of the management platform to call the class and ask questions in class.

\subsubsection{The auxiliary management function of other university administrative departments.}

In addition to the information management platform of the academic affairs office, other administrative departments are no exception. For example, the Student Affairs Office needs to have its own management platform to carry out the Second Class. The Finance department needs a management platform in line with its own business to realize daily financial management; The Personnel department needs the personnel management platform and the school administrative office needs approval document platform of the school (called OA in China) and so on.

\subsection{ICT use for AI into the platform integration}

The platform integration with AI technology is a future trend of the application of ICT in education management. The platform integration refers to the integration of information system platforms within departments and the integration of business between administrative departments on campus. What is system convergence by the ICT? For example, the academic administration system may be used in the academic administration office. The academic administration system is mainly responsible for the academic administration and student status management, while the practical administration system is mainly responsible for the arrangement and management of internship. It is possible to use four or five systems in a department due to different business. Future trends maybe is as educational administration system into the 
practice of practice management and paper management. This integration can greatly reduce the number of systems used within the department and greatly reduce the cost of system maintenance and the workload of teachers. Deep integration is between the executive branches. For example, the Academic Affairs Office has the relevant information about the students and teachers in the school, while the Personnel Office has the information of all teachers in the school, such as education background, professional title and department. The scientific research department has the relevant information of the scientific research achievements of the whole university, and the finance department has its own financial expenditure information system. If you want to write a report on the school-enterprise cooperation results of our school, you need to go to the
Financial Affairs Office to learn about the expenditure situation and the Scientific Research Office to learn about the scientific research results of the schoolenterprise cooperation. Once there is such a convergence platform. Relevant information will soon be available. Platform barriers between departments will be broken and large information sharing within the university will be achieved.

In recent years, two major areas in the tech world have become increasingly hot: $5 \mathrm{G}$ and AI. Both are disruptive technologies capable of changing the times. At present, the 5G network standard has been completed, and the $5 \mathrm{G}$ industry is in the commercial sprint stage. Let's look at Figure 3 the $5 \mathrm{G}$ use in other countries.

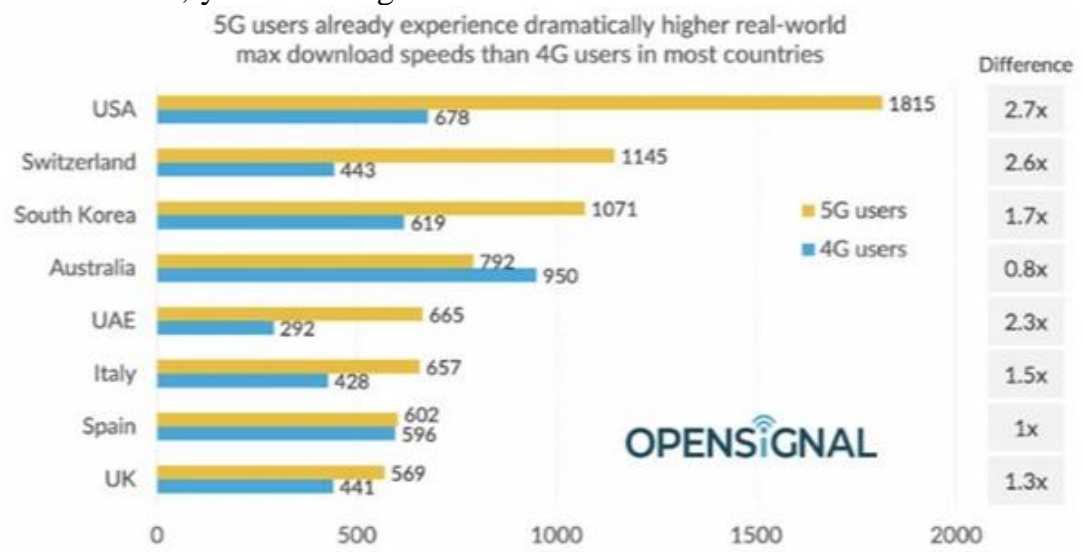

Figure 3 Comparison of commercial use of $5 \mathrm{G}$ in different countries sourced by Tengxun

In terms of AI, it is widely believed in the industry that the fourth technological revolution is another technological revolution following the steam technological revolution, the electric power technological revolution, and the computer and information technological revolution, and AI is an important driving technology of the fourth industrial revolution.

How to combine these two core technologies is a matter of great imagination. The intersection of the two can form an alternating upward trend. For example, unmanned aerial vehicles, called "aerial fireworks" in light shows, are a good case in point. Thanks to their powerful computing power and highly reliable network, unmanned aerial vehicles can construct swarm intelligence, not only for creative performance, but also for search and rescue, delivery and other fields. If this two core technologies into the existed platform in the educational field, we can imagine that teaching can make the virtual world closer to the real world, teaching contents are more vivid and teaching evaluation is more intuitive. Teaching management is more concise. Perhaps through voice commands, the platform system can achieve data search, upload and download and document approval automation. Even the teaching manager can realize the automatic generation of the evaluation report for the teaching evaluation of the semester or the whole year through the voice command.

\section{CONCLUSION}

With the continuous maturity of big data, artificial intelligence and $5 \mathrm{G}$ technologies, the application of ICT in various fields will only step into a deeper level, not to mention the application in the field of education. Both developed and developing countries will pay more attention to the integration of new technology into educational management, which makes the finished product of education more competitive. In order to improve the overall quality and competitiveness of the country's talent. The application of ICT in educational management will only become more concise, intelligent and efficient. The application of ICT in education management is bound to be more intelligent, more compatible with multi-sector platforms, more efficient data extraction and more convenient for use in the future.

This paper mainly based on the literature method, through the collection of relevant articles at home and abroad, sorting out the past and present information technology in education management and predicting the possible future development of the application trend. 
And ICT will be unstoppable in many fields in the future.

\section{ACKNOWLEDGMENT}

This paper is the phased achievement of Research and Practice of Rural Outstanding Teacher Training in Central Guangxi under Rural Revitalization Strategy, belonging to Guangxi Higher Education Undergraduate Teaching Reform Project (Project No.: 2018JGB360), 2018 Guangxi Vocational Education and Teaching Reform Research General Project "Practice-oriented Primary Education (General) Professional Curriculum Research and Practice" Project Number GXGZJG2018B125. and 2019 Guangxi Science and Technology Normal University Education And Teaching Reform Project (Key Project): Research and Practice on the Construction of Primary School English Immersion Teaching Model under the Background of "Internet +" (Project No.: 2019GKSYJGA03)

\section{REFERENCES}

[1] Bethany Christian College of Teachers' Education Information and Communication Technology. [EB/OL].https://sites.google.com/site/bethanycolle geofteacheredn/unit---1-information-andcommunication-technology. 2021.7.5

[2] Dewitt D., Alias N. Computer in Education in Developing countries:Managerial Issues. [M]. Encyclopedia of Education and Information Technology.2020:398-405.
[3] China Educationand Research Network. The Ministry of Education Issued the Key Work Points in 2021 to Actively Promote the Construction of Education

Informatization. [EB/OL] .https://www.edu.cn/info/focus/zc/20210 2/t20210204_2074919.shtml 021.7.5.

[4] Tan Haoqiang. Computer Popularization and Its Enlightenment:To commemorate the 30th anniversary of the popularization of computers in China. [J]. Computer Education,2011(17):1-4.

[5] Zhao Hehe and Li Jintao. Research on the Application of Information Technology in Educational Management of Colleges and Universities. $[\mathrm{J}]$. Chinese and Foreign Entrepreneurs,2019(12):191.

[6] Lou Feiyan. Research on Application of Information Technology in Educational Management of Higher Vocational Colleges. [J].China ManagementIn formationization, 2018(21):142-144.

[7] Wang Shenglin. Application of Information Technology in Education and Teaching Management. [J]. Teacher.2021.93-94.

[8] Liu Huaxiang. Research on the Application of Information Technology in Education Management of Application-oriented Colleges and Universities. [J]. Higher Education.2021(11):30-31. 